Article

\title{
Development of Crystalline $\mathrm{Cu}_{2} \mathrm{~S}$ Nanowires via a Direct Synthesis Process and Its Potential Applications
}

\author{
Chih-Yen Chen ${ }^{1, * \mathbb{C}}$, Jian-Ru Jiang ${ }^{2}$, Wen-Shuo Chuang ${ }^{1}$, Ming-Song Liu $^{2}$ and \\ Sheng-Wei Lee ${ }^{2, *}$ \\ 1 Department of Materials and Optoelectronic Science, National Sun Yat-Sen University, \\ Kaohsiung 804, Taiwan; egg037105218@yahoo.com.tw \\ 2 Institute of Materials Science and Engineering, National Central University, Taoyuan 320, Taiwan; \\ icq200148@gmail.com (J.-R.J.); 40232146@gm.nfu.edu.tw (M.-S.L.) \\ * Correspondence: cychen@mail.nsysu.edu.tw (C.-Y.C.); swlee@g.ncu.edu.tw (S.-W.L.)
}

Received: 30 January 2020; Accepted: 21 February 2020; Published: 24 February 2020

\begin{abstract}
Large-scale and uniform copper(I) sulfide $\left(\mathrm{Cu}_{2} \mathrm{~S}\right)$ nanowires have been successfully synthesized via a cheap, fast, easily handled, and environmentally friendly approach. In addition to the reductive properties of the biomolecule-assisted method, they also have a strong shapeor size-directing functionality in the reaction process. The field-emission properties of the $\mathrm{Cu}_{2} \mathrm{~S}$ nanowires in a vacuum were studied by the Folwer-Nordheim $(\mathrm{F}-\mathrm{N})$ theory. The $\mathrm{Cu}_{2} \mathrm{~S}$ nanowires have a low turn-on field at $1.19 \mathrm{~V} / \mu \mathrm{m}$ and a high enhancement factor $(\beta)$ of 19,381 . The photocatalytic degradation of $\mathrm{Cu}_{2} \mathrm{~S}$ nanowires was investigated by the change in the concentrations of rhodamine $\mathrm{B}$ $(\mathrm{RhB})$ under UV illumination. These outstanding results of $\mathrm{Cu}_{2} \mathrm{~S}$ nanowires indicate that they will be developed as good candidates as electron field emitters and chemical photocatalysts in future nanoelectronic devices.
\end{abstract}

Keywords: $\mathrm{Cu}_{2} \mathrm{~S}$ nanowires; nanomaterials; vacuum; field emission; photocatalytic degradation; environmentally friendly approach

\section{Introduction}

Over the past decades, a variety of nanostructured semiconductors with well-controllable size, shape, and composition have been widely developed and applied in many kinds of fields, such as catalysis, size-effect, photocatalytic, and biomaterial applications [1-3]. Some important studies have indicated that the properties of nanomaterials depend on their morphologies and sizes, so that their chemical and physical properties are quite different from each other in bulk materials [4-7]. Among various metal chalcogenide semiconductor nanostructures, the copper(I) sulfide $\left(\mathrm{Cu}_{2} \mathrm{~S}\right)$ nanostructure is regarded as a potential material for future applications in optoelectronic devices [8-10]. $\mathrm{Cu}_{2} \mathrm{~S}$ is an excellent p-type semiconductor material with an indirect bandgap of $1.2 \mathrm{eV}$, and it could be applied in photovoltaics [9], nanoscale sensors [11,12], and cathodes for lithium-ion batteries [13-15].

A lot of efforts have been devoted in recent years to developing semiconductor photocatalysts with high photocatalytic activities for environmental protection [8,11,13-15]. Most photocatalytic degradation studies have focused on the use of nano-crystalline titanium oxides $\left(\mathrm{TiO}_{2}\right)[16,17]$, but their photocatalytic efficiency is quite poor, especially under visible light irradiation. In this respect, metal chalcogenide semiconductors have suitable photocatalytic activities under solar irradiation, so they might be good alternatives for replacing the $\mathrm{TiO}_{2}$. A variety of different $\mathrm{Cu}_{2} \mathrm{~S}$ nanostructures such as nanowires, nanoplates, and nanocrystals have been synthesized using diverse routes [11-15]. Previous 
studies have developed several synthesis routes for the growth of $\mathrm{Cu}_{2} \mathrm{~S}$ nanowire arrays, such as thermal evaporation processes and autoclave-assisted hydrothermal processes [18-20]. However, we have reviewed these synthesis methods carefully, but many of these are achieved with toxic chemicals. Many of these are strictly regulated because they are toxic, bio-accumulative, disruptive to hormones, and carcinogenic.

In this study, large-scale and uniform free-standing semiconducting copper(I) sulfide $\left(\mathrm{Cu}_{2} \mathrm{~S}\right)$ nanowire arrays have been successfully synthesized on copper substrates via a fast, easily handled, and environmentally friendly approach. The innovative reduction method, which combines ethylenediamine (En) and hydrazine in an alkali solution, is demonstrated to be effective in synthesizing copper nanowires. Furthermore, $\mathrm{Cu}_{2} \mathrm{~S}$ nanowires were investigated experimentally in detail for their filed emitted electronic and photocatalytic properties. A photocatalyst of $\mathrm{Cu}_{2} \mathrm{~S}$ structures was investigated by photocatalytic degradation of rhodamine $\mathrm{B}(\mathrm{RhB})$ under UV illumination. The previous results indicate that surface area would play a significant factor in the efficiency of photocatalysis, since photocatalytic reaction occurred on the surface $[9,11,12]$. On the other hand, the $\mathrm{Cu}_{2} \mathrm{~S}$ nanowires also show a low turn-on field $(1.19 \mathrm{~V} / \mu \mathrm{m})$ and high field enhancement factor $(\beta=19,381)$. A smaller cross-sectional area of an emitter will enhance its field-emission performance. Because the tip of the free-standing nanowire has a smaller cross-sectional area, our $\mathrm{Cu}_{2} \mathrm{~S}$ nanowires hence have better filed emission properties than other nanoscale-emitting materials or the same bulk crystalline solids in the previous reports $[18,21,22]$. These availabilities of $\mathrm{Cu}_{2} \mathrm{~S}$ nanowires will not only enable new types of applications, but also allow the performance of photoelectricities to be enhanced in future devices.

\section{Materials and Methods}

\subsection{Synthesis of $\mathrm{Cu}_{2} \mathrm{~S}$ Nanowire Structure}

In a typical procedure, $10 \mathrm{~g}$ sodium hydroxide $(\mathrm{NaOH}, \geq 98 \%$, Sigma-Aldrich, St. Louis, $\mathrm{MO}$, USA) were dissolved in $40 \mathrm{~mL}$ distilled water and heated to $70^{\circ} \mathrm{C}$. At a constant $70^{\circ} \mathrm{C}, 1 \mathrm{~g} \mathrm{~L}$-Cystine, $7 \mathrm{~mL}$ ethylenediamine ( $\geq 99 \%$, Sigma-Aldrich), and $40 \mu \mathrm{L}$ hydrazine ( $98 \%$, Sigma-Aldrich) were added into the solution. The cleaned copper foil (Nan-ya Plastics Corporation) was then placed into the mixture for $10 \mathrm{~h}$, and the final product was a black film on the $\mathrm{Cu}$ substrate. The products on the copper substrate were washed several times with ethanol and Deionized water (DI water), and then dried in an air atmosphere.

\subsection{Microstructure Characterization}

Several precision facilities were thoroughly used for the morphological characterization of the $\mathrm{Cu}_{2} \mathrm{~S}$ nanowires. The microstructure and chemical composition were characterized by using a field-emission scanning electron microscope (FE-SEM; Quanta 200, FEI Company, Hillsboro, OR, USA) equipped with an energy-dispersive $X$-ray spectrometer. High-resolution lattice images were obtained with an ultrahigh vacuum high-resolution transmission electron microscope (HRTEM, JEM-2000FX II, JEOL, Ltd., Tokyo, Japan), operating at $200 \mathrm{keV}$ with a point-to-point resolution of $0.14 \mathrm{~nm}$. X-ray diffraction (XRD, D2 Phaser, Bruker Corporation, Karlsruhe, Germany) was used to characterize the crystal structure of the $\mathrm{Cu}_{2} \mathrm{~S}$ nanowires over copper foil, recorded in a Bruker D8A diffractometer by using $\mathrm{Cu}$ $\mathrm{K} \alpha$ radiation. It was operated at $40 \mathrm{kV}$ and $40 \mathrm{~mA}$ with a scan rate of $0.04^{\circ}$ per step.

\subsection{Measurement of Photodegradation of RhB}

The photocatalytic performance of $\mathrm{Cu}_{2} \mathrm{~S}$ was evaluated by the degradation of Rhodamine $\mathrm{B}(\mathrm{RhB}$, HPLC, Sigma-Aldrich) under UV irradiation using a 200 W Mercury-Xenon (HgXe) arc lamp bulb. Degradation tests were performed by using films with geometrical surfaces of $0.9 \times 0.9 \mathrm{~cm}^{2}$, immersed in $3 \mathrm{~mL} \mathrm{RhB}$ solution with the initial concentration of $5 \mu \mathrm{M}$. At various irradiation times, the UV-visible absorption spectrum of the solution was measured by using a spectrophotometer (Evolution 60S, 
Thermo Scientific, Waltham, MA, USA), and the concentration was estimated by the integration of the absorption peak.

\subsection{The Electron Field Emission Measurements}

The field-emission output of $\mathrm{Cu}_{2} \mathrm{~S}$ nanowires was carried out in a vacuum chamber under the pressure of $1 \times 10^{-7}$ torr at room temperature. The measurement distances between the anode and the emitting surface of the $\mathrm{Cu}_{2} \mathrm{~S}$ nanowires were controlled in $100 \mu \mathrm{m}$. The GDM-8246 (GW-Instek Ltd.) instrument was used to measure the current density (I) and electric field (E) characteristics. It was necessary to run over emission cycles for 50 times in order to obtain stable and reproducible I-E characteristics.

\section{Results}

\subsection{Growth and Structural Characterizations of $\mathrm{Cu}_{2} \mathrm{~S}$ Nanowires}

By utilizing the combination of cystine, a compound which has the formula $\left(\mathrm{SCH}_{2} \mathrm{CH}\left(\mathrm{NH}_{2}\right) \mathrm{CO}_{2} \mathrm{H}\right)_{2}$, and metal chelating chemistry, successful synthesis of $\mathrm{Cu}_{2} \mathrm{~S}$ nanowires on the copper substrate was based on a biomolecule-assisted method. Cystine is an ordinary dimeric amino acid formed by the oxidation of two cysteine molecules that covalently link to make a disulfide bond. The disulfide link is readily reduced to give the corresponding thiol cysteine when it is heated. As a sulfur-containing amino acid, L-cysteine has been also proposed as a structure-directing agent in the synthesis of metal sulfide nanostructures, such as $\mathrm{CdS}$ and $\mathrm{Bi}_{2} \mathrm{~S}_{3}$ [23-25]. In this study, L-cystine was utilized not only as the structure-directing molecule, but also as a sulfur source to prepare the metal sulfide nanostructures. This process is so convenient that $\mathrm{Cu}_{2} \mathrm{~S}$ nanowires do not need to be synthesized in a common high-pressure autoclave.

Figure 1 illustrates a possible chemical reaction pathway and growth mechanism of the $\mathrm{Cu}_{2} \mathrm{~S}$ nanowire arrays in experiments. The ethylenediamine molecules have a strong coordinating ability and function in metal chelation or in mediating the electron transfer in the reaction system. When the clean copper substrate was placed into the mixture, the ethylenediamine could play a role in activating the surface of the metal substrate and in electron transfer in the reacting system [26,27]. On the other hand, the stability of the Cu-ethylenediamine $(\mathrm{Cu}-\mathrm{En})$ metal complex was decreased by increasing the temperature, and a sulfide ion $\left(\mathrm{S}^{2-}\right)$ was produced from the dissociation of cysteine so that $\mathrm{S}^{2-}$ could react quickly with the $\mathrm{Cu}$-En complex. The ethylenediamine molecules of the unstable inorganic-organic complex of $\mathrm{Cu}_{2} \mathrm{~S}$-En molecular precursors eventually disappeared [28-30], resulting in the formation of $\mathrm{Cu}_{2} \mathrm{~S}$ nanocrystals, which are located on the copper substrate in Figure 1.

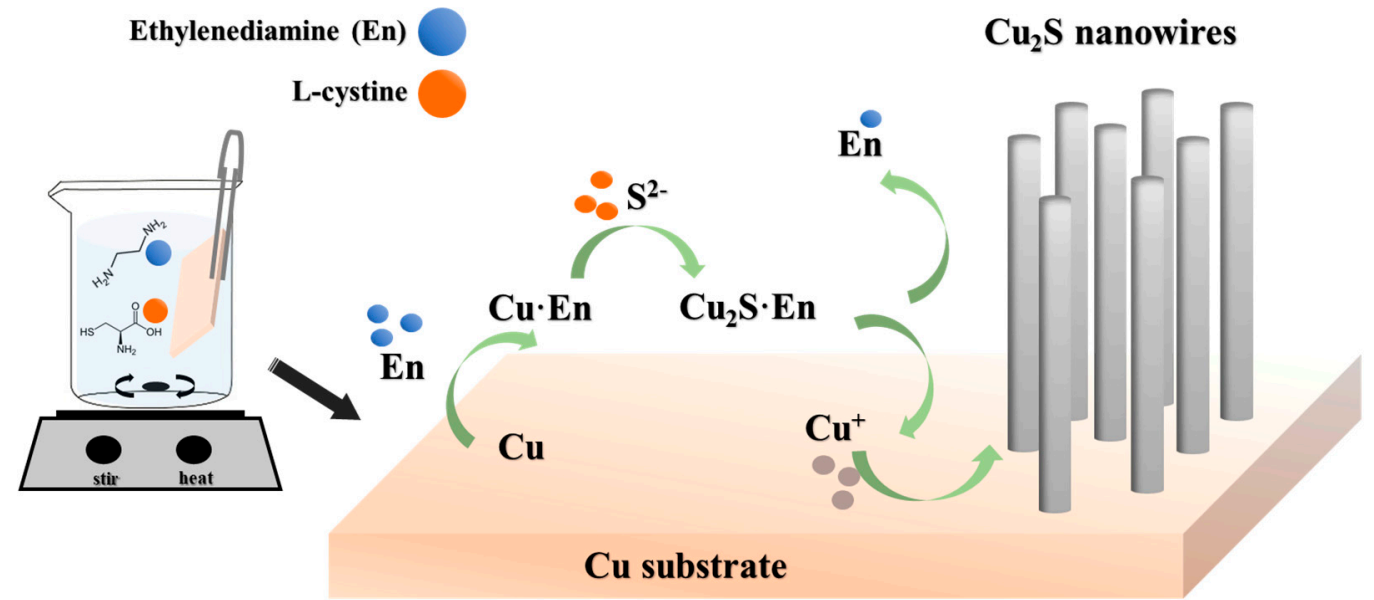

Figure 1. The growth mechanism of the copper(I) sulfide $\left(\mathrm{Cu}_{2} \mathrm{~S}\right)$ nanowire arrays. 
In order to understand the effects of the different reaction conditions on the growth of the free-standing $\mathrm{Cu}_{2} \mathrm{~S}$ nanowires, a series of experiments have been carried out by examining the aging time, the amount of sodium hydroxide, and the volume of ethylenediamine. Figure 2 shows a series of low-magnification SEM images of the as-synthesized product grown on the copper substrate. It is well known that synthesizing a $\mathrm{Cu}$-En metal complex results from a copper ion and a ligand of ethylenediamine solution because of a Lewis acid-base interaction. The sulfidation rate has to be studied experimentally in order to obtain high regularity for the $\mathrm{Cu}_{2} \mathrm{~S}$ nanowires. The high $\mathrm{pH}$ value in the alkali condition is also essential to let the sulfur anions diffuse to the copper substrate slowly and to prevent the rapid sulfidation rate of the copper substrate. Furthermore, a chemical agent of sodium hydroxide is added, which can maintain a strong alkaline environment with a high $\mathrm{pH}$ value and also accelerates the dissolution of cystine in the solution. Figure $2 \mathrm{a}-\mathrm{d}$ shows the morphologies of $\mathrm{Cu}_{2} \mathrm{~S}$ nanowires grown in various amounts of alkali solution by changing the amounts of sodium hydroxide $(\mathrm{NaOH})$ from $5,7.5$, and $10 \mathrm{~g}$ to $20 \mathrm{~g}$ with $1 \mathrm{~g}$ cysteine and $7 \mathrm{~mL}$ ethylenediamine at $70{ }^{\circ} \mathrm{C}$ for $10 \mathrm{~h}$. The other four SEM images of as-prepared $\mathrm{Cu}_{2} \mathrm{~S}$ nanowires grown with $10 \mathrm{~g} \mathrm{NaOH}, 1 \mathrm{~g}$ cysteine, and $7 \mathrm{~mL}$ ethylenediamine at $70{ }^{\circ} \mathrm{C}$ for $1,3,5$, and $10 \mathrm{~h}$, respectively, as shown in Figure 2e- $\mathrm{h}$. In comparison with the SEM images of Figure 2e,h, the dimensions and lengths of the nanowires were also enlarged with a long aging time. Prolonging the reaction time could lead to an increase in the dimensions and lengths of the $\mathrm{Cu}_{2} \mathrm{~S}$ nanowires rather than the growth of a higher density of $\mathrm{Cu}_{2} \mathrm{~S}$ nanowires. The results also indicate that the growth of the existing nucleus that has been formed at a certain location is easier than the formation of new nuclei $[14,31]$. The influence of the volume of ethylenediamine in our systems has also been investigated. Volumes of 4, 7, and $10 \mathrm{~mL}$ ethylenediamine were added respectively into the reaction solutions with $10 \mathrm{~g}$ sodium hydroxide at $70{ }^{\circ} \mathrm{C}$ for $10 \mathrm{~h}$. The SEM images show that a certain amount of ethylenediamine was indispensable for controlling the morphology and density of nanowires, as shown in Figure S1 (see supplementary file).
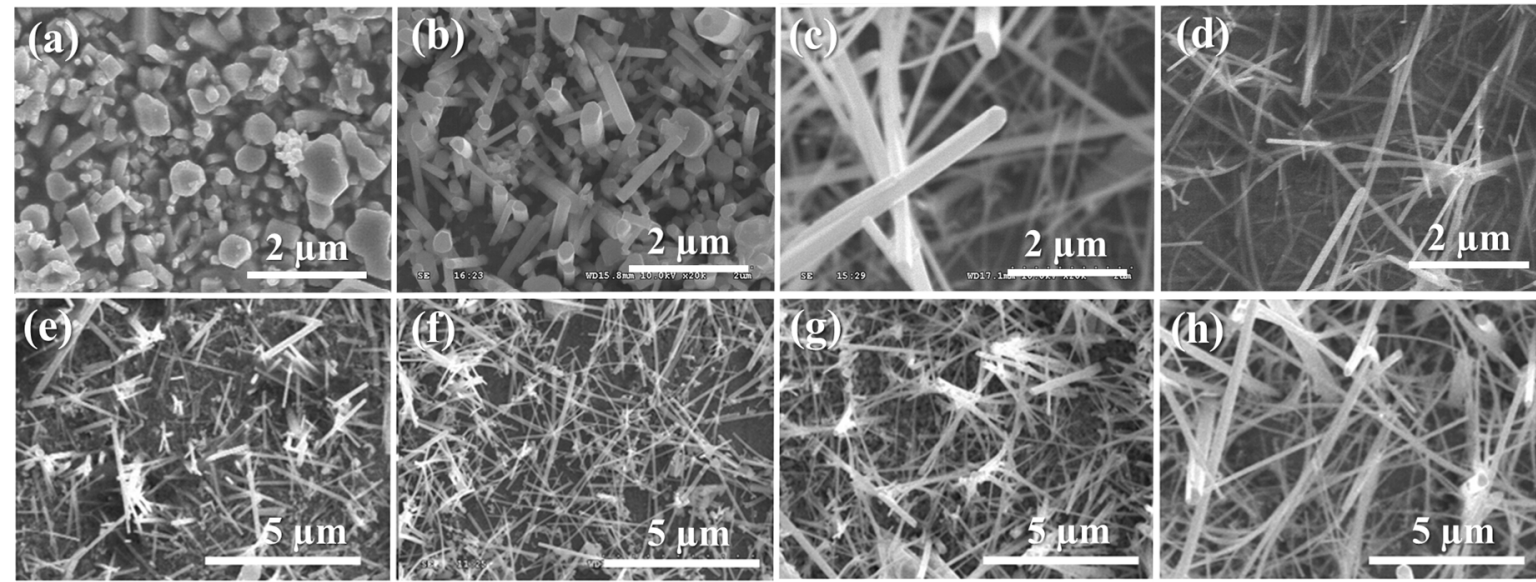

Figure 2. SEM images of as-prepared free-standing $\mathrm{Cu}_{2} \mathrm{~S}$ nanowires grown under different reaction conditions. For the first four conditions, (a) 5, (b) 7.5, (c) 10, and (d) $20 \mathrm{~g} \mathrm{NaOH}$ are added with $1 \mathrm{~g}$ cysteine and $7 \mathrm{~mL}$ ethylenediamine at $70^{\circ} \mathrm{C}$ for $10 \mathrm{~h}$. The other four conditions $10 \mathrm{~g} \mathrm{NaOH}, 1 \mathrm{~g}$ cysteine, and $7 \mathrm{~mL}$ ethylenediamine at $70{ }^{\circ} \mathrm{C}$ are controlled for (e) 1 , (f) $3,(\mathrm{~g}) 5$, and (h) $10 \mathrm{~h}$.

After comparing these SEM images of Figure 2 and Figure S1 to explore the optimum value of the experiment, high-quality $\mathrm{Cu}_{2} \mathrm{~S}$ nanowires were successfully synthesized using the parameters of $10 \mathrm{~g} \mathrm{NaOH}, 1 \mathrm{~g}$ cysteine, and $7 \mathrm{~mL}$ ethylenediamine, which were added respectively into the reaction solution, and finally, it was heated at $70{ }^{\circ} \mathrm{C}$ for $10 \mathrm{~h}$. Figure $3 \mathrm{a}$ shows a low-magnification SEM image of the as-synthesized high-quality $\mathrm{Cu}_{2} \mathrm{~S}$ nanowires grown on the copper substrate. The detailed parameters of this experiment are provided in the Materials and Methods section. The highly ordered $\mathrm{Cu}_{2} \mathrm{~S}$ nanowire arrays covered the entire area of the copper substrate compactly and uniformly. Figure $3 \mathrm{~b}$ is a tilting-angle view SEM image of well-aligned $\mathrm{Cu}_{2} \mathrm{~S}$ nanowire arrays, and the average 
length of the $\mathrm{Cu}_{2} \mathrm{~S}$ nanowires is about $30 \mu \mathrm{m}$. These nanowires have a quite high length-to-width ratio. The structure and morphology of the nanowires were further studied using transmission electron microscope (TEM), as shown in Figure $3 \mathrm{c}$,d. The Figure $3 \mathrm{c}$ indicates a diameter of the $\mathrm{Cu}_{2} \mathrm{~S}$ nanowires of close to $50 \mathrm{~nm}$. In Figure 3d, a lattice spacing obtained from a high-resolution TEM image is about $0.239 \mathrm{~nm}$, corresponding to the interplanar distance of the (1 111 1) planes of monoclinic $\mathrm{Cu}_{2} \mathrm{~S}$ crystals. The structures of the $\mathrm{Cu}_{2} \mathrm{~S}$ nanowire arrays on copper substrate were also determined by means of high-resolution $\theta-2 \theta$ (theta) X-ray diffraction measurements. As shown in Figure $3 e$, all of the diffraction peaks of the as-grown sample can be ascribed to the single phase of the orthorhombic-structured $\mathrm{Cu}_{2} \mathrm{~S}$ crystal phase (JCPDS No. 23-0961) with lattice constants of $\mathrm{a}=1.350, \mathrm{~b}=2.732$, and $\mathrm{c}=1.185 \mathrm{~nm}$ [14]. It should be noted that there are three additional peaks $\left(2 \theta=43.32^{\circ}, 50.45^{\circ}\right.$, and $\left.74.13^{\circ}\right)$ corresponding to the substrate copper foil.

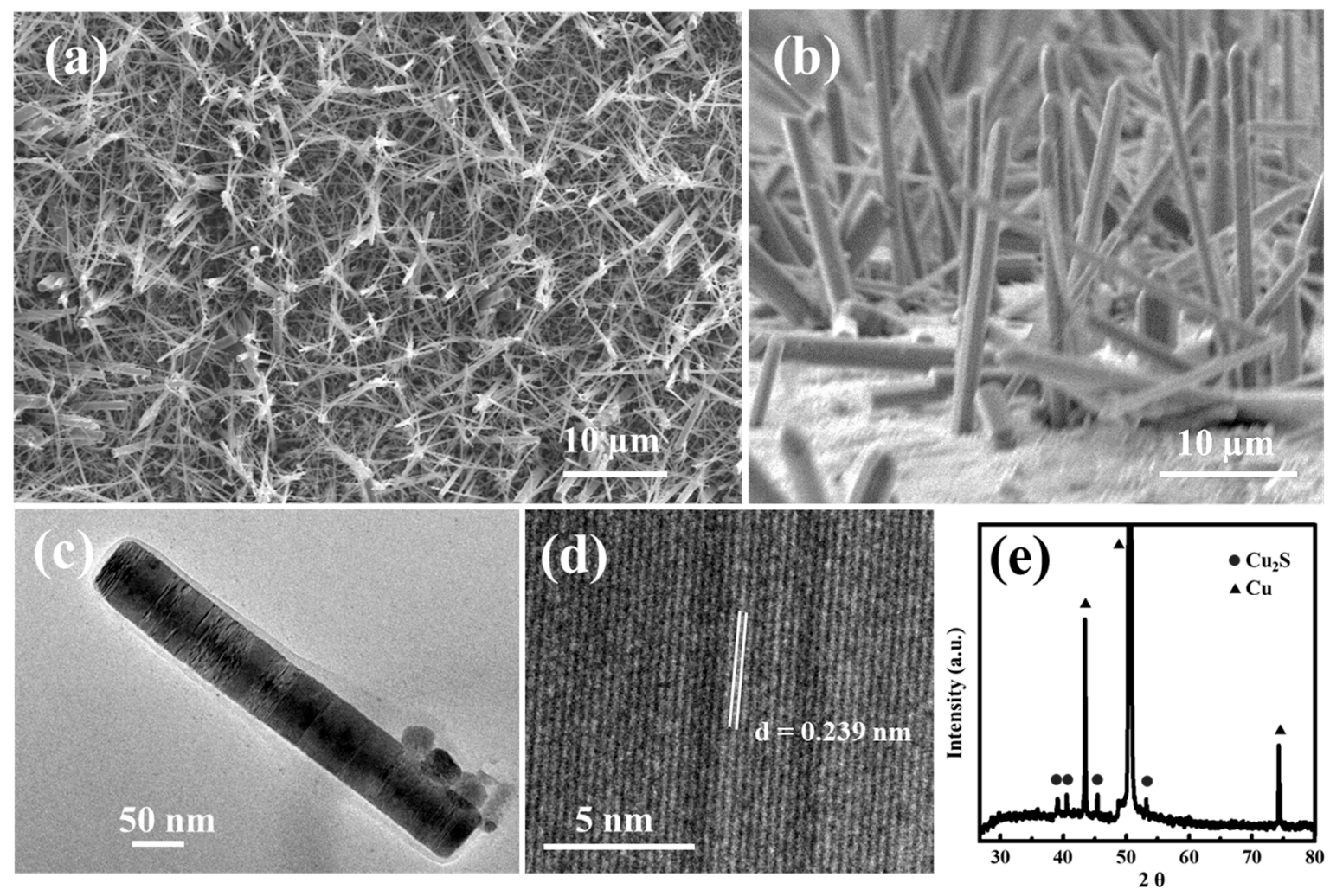

Figure 3. Structural characterizations of $\mathrm{Cu}_{2} \mathrm{~S}$ nanowires. The top-view (a) and tilt-view (b) SEM images of $\mathrm{Cu}_{2} \mathrm{~S}$ nanowires. (c) High-magnification and (d) high-resolution TEM image of $\mathrm{Cu}_{2} \mathrm{~S}$ nanowires. (e) The XRD patterns of $\mathrm{Cu}_{2} \mathrm{~S}$ nanowires.

\subsection{ElectronField Emission Property}

The materials of interest from field emission have been classified as metallic materials, including carbon nanotubes (CNTs) [32], gold [21], metal silicides [33,34], or wide-bandgap and semiconducting materials such as $\mathrm{ZnO}$ [35], $\mathrm{WO}_{3}$ [36], and $\mathrm{CuO}$ [37] nanowires.

The field-emission properties of $\mathrm{Cu}_{2} \mathrm{~S}$ nanoemitters were measured, as shown in Figure $4 \mathrm{a}$. The $\mathrm{Cu}_{2} \mathrm{~S}$ nanowires vertically grown on $\mathrm{Cu}$ substrates show great field-emission properties; the field-emission current density-electrical field (J-E) curve is presented in Figure $4 \mathrm{~b}$. The turn-on field is $1.19 \mathrm{~V} / \mu \mathrm{m}$; this value was defined as the applied voltage to produce emitting current density of 
$10 \mu \mathrm{A} / \mathrm{cm}$. The field-emission characteristics were theoretically evaluated by the Fowler-Nordheim $(\mathrm{F}-\mathrm{N})$ equation (Equation (1)) [38].

$$
\mathrm{J}(\mathrm{E})=\mathrm{AE}^{2} \varnothing^{-1} \exp \left(\frac{-\mathrm{B} \varnothing^{\frac{3}{2}}}{\beta E}\right)
$$

where $\mathrm{A}$ and $\mathrm{B}$ are two constants, corresponding to $1.56 \times 10^{-10}\left[\mathrm{AV}^{-2}(\mathrm{eV})\right]$ and $6.83 \times 10^{3}\left[\mathrm{~V}\left(\mathrm{eV}^{-3 / 2}\right)\right.$ $\left(\mu \mathrm{m}^{-1}\right)$ ], respectively [38]. E is the applied field, $\beta$ is the field-enhancement factor of the nanowires, $\varnothing$ is the work function of the emitter, which is $5.6 \mathrm{eV}$ for $\mathrm{Cu}_{2} \mathrm{~S}$, and $\mathrm{J}$ is the current density. The emission behavior can be examined from the linearity of the curve by the corresponding Fowler-Nordheim plot $\left(\ln \left(J / E^{2}\right)-1 / E\right.$ curve) of the device after 50 tests (see upper-left inset image in Figure $4 \mathrm{~b}$ ). The maximum emission current can reach up to $55 \mu \mathrm{A} / \mathrm{cm}^{2}$ as the applied voltage can reach over $1000 \mathrm{~V}$.
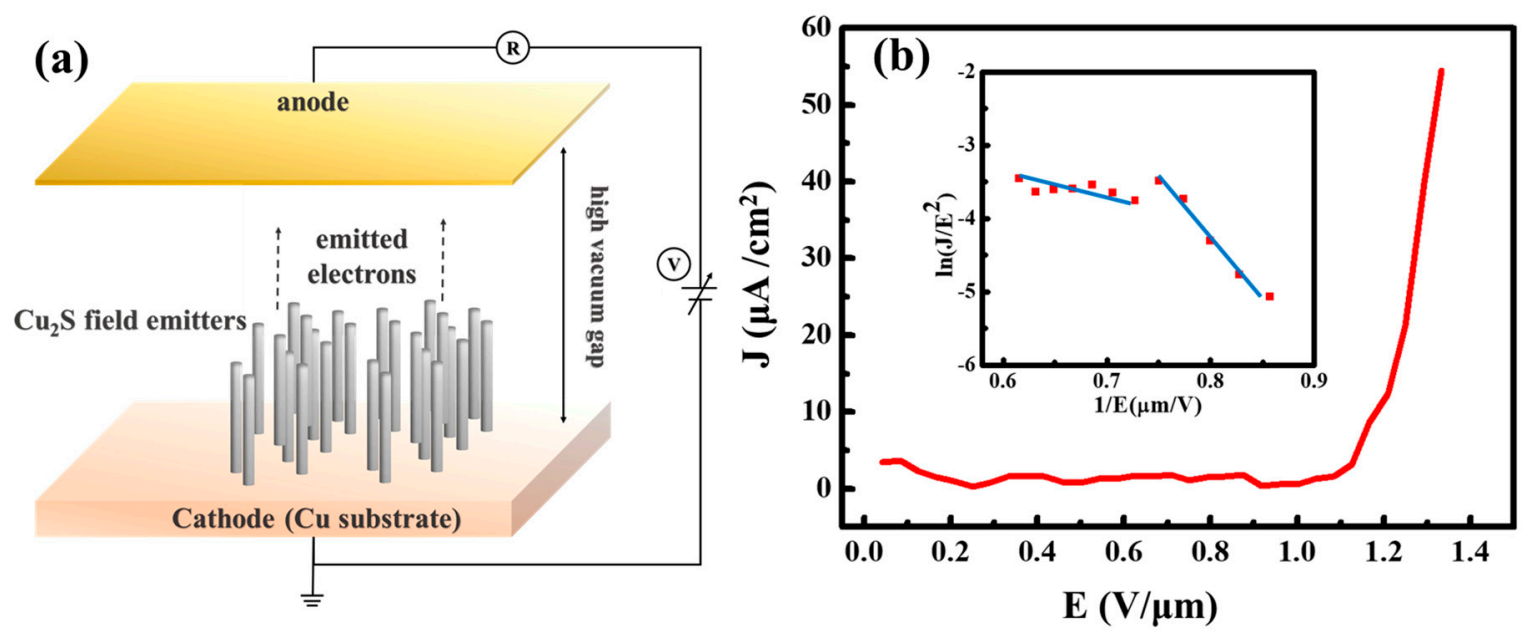

Figure 4. (a) Schematic of the field-emission measurement setup. (b) Field-emission current (J) versus applied electric field (E) plot measured at $100 \mu \mathrm{m}$ between cathode and anode separation and pressure of $1 \times 10^{-7}$ torr. Its inset image is the Fowler-Nordheim $(\mathrm{F}-\mathrm{N})$ plot of the $\mathrm{Cu}_{2} \mathrm{~S}$ nanowires.

The linearity of these curves implies that the field emission from these $\mathrm{Cu}_{2} \mathrm{~S}$ nanowires follows the F-N theory and exhibits two negative linear associations in the measured range. At low bias voltages, the field-emission mechanism obeys the properties of the traditional Fowler-Nordheim equation, while the field emission behavior under high bias voltages deviates from the Fowler-Nordheim equation, but a linear relationship on the F-N coordinate still appears. Several reasons have been used to explain the deviation of field emission from Fowler-Nordheim behavior. The deviation from the F-N plot at high bias voltages has frequently been attributed to the space charge effect, localized states, and gas adsorbates $[39,40]$.

At the microscopic point, the $\beta$ values should be experimentally studied. The $\beta$ factor, reflecting the degree of field emission for the tip shape on a planar surface, can be estimated by the slope $\left(-\mathrm{B} \Phi^{3 / 2} / \beta\right)$ of the $\mathrm{F}-\mathrm{N}$ plot. At the applied high field, the $\beta$ value indicates that the barrier-tunneling mechanism is responsible for the field emission. We estimate the $\beta$ value from the F-N plot. The field enhancement factors $\beta_{1}$ and $\beta_{2}$ are 19,381 and 5787, respectively, which are much higher than in the previous report [18,22,32-37]. Furthermore, some previous articles have reported that the $\beta$ value is related to the geometry of the crystal specified by the radius of the curvature of the tip [41-43] and other factors, such as the emission height, the crystal structure, conductivity, and the nanostructure density [44]. 


\subsection{Photocatalytic Activity}

To further measure the photocatalytic properties of the $\mathrm{Cu}_{2} \mathrm{~S}$ nanostructured wires, a series of the reactions were investigated for their application of photocatalysis degradation from 1 to $8 \mathrm{~h}$. The results of the photocatalytic activity of the $\mathrm{Cu}_{2} \mathrm{~S}$ nanowire arrays are presented in Figure 5. The UV-visible absorbance spectra of the $5 \mu \mathrm{M}$ rhodamine $\mathrm{B}(\mathrm{RhB})$ solution with the $\mathrm{Cu}_{2} \mathrm{~S}$ photocatalyst at different irradiation times were measured in Figure $5 \mathrm{a}$. This indicates that $\mathrm{Cu}_{2} \mathrm{~S}$ nanowire photocatalysts have an inclination to decrease the UV-visible absorbed wavelength of $554 \mathrm{~nm}$ for a longer period of irradiation time. $\mathrm{Cu}_{2} \mathrm{~S}$ nanowires have great photocatalytic properties in comparison with the same bulk-type materials due to the larger specific surface area $[45,46]$. Figure $5 \mathrm{~b}$ shows that our $\mathrm{Cu}_{2} \mathrm{~S}$ nanowires have a degradation rate percentage of $47.4 \%$ after continuing testing for $8 \mathrm{~h}$. Figure $5 \mathrm{c}$ reveals the photodegradation kinetics of rhodamine $\mathrm{B}$. The photodegradation of dyes follows the first-order reaction described by the Langmuir-Hinshelwood (L-H) mechanism (Equation (2)) [20,47,48].

$$
\ln C=\ln C_{0}-k t
$$

where $\mathrm{C}_{0}$ is the initial concentration of the aqueous solution of dyes, $\mathrm{C}$ is the corresponding concentration of the aqueous solution of dyes which was measured at various irradiation times, $\mathrm{K}$ is a constant of photodegradation rate. After the first-order kinetics calculation, the photodegradation rate constant $(\mathrm{K})$ was obtained by plotting $-\ln \left(\mathrm{C} / \mathrm{C}_{0}\right)$ as a function of the various irradiation times. The experimental results indicate that surface area would play a significant role in the efficiency owing to the photocatalytic reaction which occurred exactly on the surface. A photocatalyst with a higher specific surface area is important in the enhancement of photocatalytic performance due to more surface active sites and photocatalytic reaction centers.
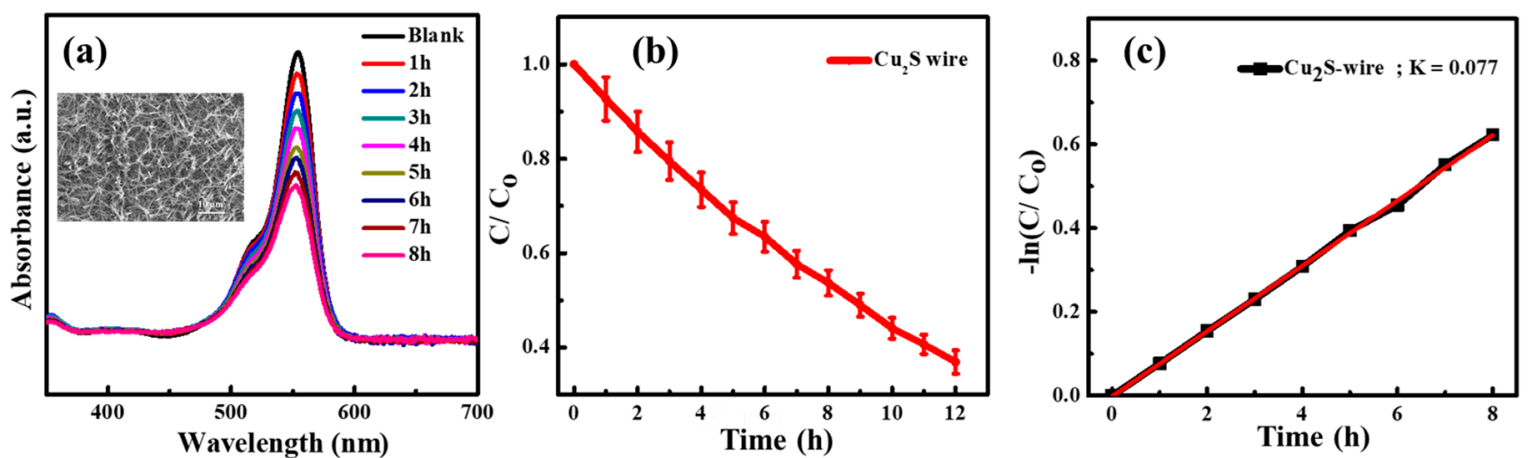

Figure 5. The illustrations display the performance of the photocatalytic activity of the $\mathrm{Cu}_{2} \mathrm{~S}$ nanowires over various irradiation periods. (a) UV/Vis absorption intensity of the RhB with a series of various times. The upper insert is an SEM image of the experimental sample. (b) Photocatalytic degradation of RhB under UV illumination. (c) The kinetic formula of RhB photodegradation, $\mathrm{K}$, is a constant of photodegradation rate.

Generally, the photoelectrochemical performance of semiconductors mainly depends on the generation of the photoinduced electron, separation of electron-hole pairs, and efficiency of charge-carrier transfer. The previous works of literature have shown that enhanced photoactivity of metal chalcogenide semiconductors such as $\mathrm{Cu}_{2} \mathrm{~S}$ and $\mathrm{CdS}$ [49-51] is primarily attributed to the improved lifetime and transfer of photogenerated charge carriers. The value of the specific surface area does not mainly determine the efficiency of the photoactive reaction, and the study of the detailed mechanism still needs further investigations. 


\section{Conclusions}

The free-standing, single-crystal $\mathrm{Cu}_{2} \mathrm{~S}$ nanowires have been successfully produced on copper metal substrates via a one-step template-free solution route. The morphology of the $\mathrm{Cu}_{2} \mathrm{~S}$ nanowires is needlelike with an average length of $30 \mu \mathrm{m}$ and average diameter of $50 \mathrm{~nm}$. Ethylenediamine plays an important role in electron transfer in redox reactions and in the formation of binary chalcogenide nanowires. The dissolution of chalcogen in ethylenediamine also affects the formation of chalcogenides. In addition, the single-crystalline $\mathrm{Cu}_{2} \mathrm{~S}$ nanowires exhibit outstanding properties with a low turn-on field of $1.19 \mathrm{~V} / \mu \mathrm{m}$ and high current density of $55 \mu \mathrm{A} / \mathrm{cm}^{2}$ according to the Folwer-Nordheim (F-N) theory, as well as a reproducible value of the field-enhancement factor $\beta_{1}$ of 19,381 and $\beta_{2}$ of 5787, respectively. On the other hand, because of their excellent optical performance, the $\mathrm{Cu}_{2} \mathrm{~S}$ nanowires are good photocatalysts which also showed effective photocatalytic activity, and RhB can be degraded rapidly with UV illumination at room temperature. The reliability test indicated that the photocatalytic reaction of our $\mathrm{Cu}_{2} \mathrm{~S}$ nanowires was highly efficient during periods of continuing specialty testing. Our $\mathrm{Cu}_{2} \mathrm{~S}$ nanowires have a degradation rate of $47.4 \%$ after an $8 \mathrm{~h}$ irradiating reaction. The above outstanding results warrant possible applications for $\mathrm{Cu}_{2} \mathrm{~S}$ nanowires as electron field emitters and chemical photocatalysts in future nanoelectronic devices.

Supplementary Materials: The following are available online at http://www.mdpi.com/2079-4991/10/2/399/s1, Figure S1: SEM images of as-prepared free standing $\mathrm{Cu}_{2} \mathrm{~S}$ nanowire grown under different reaction conditions. The three conditions are added (a) $4 \mathrm{~mL}$, (b) $7 \mathrm{~mL}$, (c) $10 \mathrm{~mL}$ ethylenediamine with $10 \mathrm{~g}$ sodium hydroxide at $70{ }^{\circ} \mathrm{C}$ for $10 \mathrm{~h}$.

Author Contributions: Conceptualization, C.-Y.C. and S.-W.L.; methodology, C.-Y.C. and J.-R.J.; software, C.-Y.C. and J.-R.J.; validation, C.-Y.C., and J.-R.J.; formal analysis, C.-Y.C., J.-R.J., and S.-W.L.; investigation, C.-Y.C., J.-R.J., W.-S.C., and M.-S.L.; data curation, C.-Y.C., J.-R.J., W.-S.C., M.-S.L., and S.-W.L.; writing-original draft preparation, C.-Y.C. and J.-R.J.; writing-review and editing, C.-Y.C.; project administration, C.-Y.C. and S.-W.L.; supervision, C.-Y.C.; funding acquisition, C.-Y.C. and S.-W.L. All authors have read and agreed to the published version of the manuscript.

Funding: This research was funded by Ministry of Science and Technology of Taiwan (MOST), grant number MOST 107-2112-M-110-013-MY3 and MOST 108-2811-M-110-533.

Acknowledgments: The authors gratefully acknowledge the MOST of Taiwan under the project MOST 107-2112-M-110-013-MY3 and MOST 108-2811-M-110-533. We also appreciated the support for analysis from the Precision Instrument Center of National Sun Yat-sen University (NSYSU) and the National Central University (NCU) in Taiwan.

Conflicts of Interest: The authors declare no conflict of interest.

\section{References}

1. Narayanan, R.; El-Sayed, M.A. Effect of Catalysis on the Stability of Metallic Nanoparticles: Suzuki Reaction Catalyzed by PVP-Palladium Nanoparticles. J. Am. Chem. Soc. 2003, 125, 8340-8347. [CrossRef]

2. Peng, M.; Ma, L.-L.; Zhang, Y.-G.; Tan, M.; Wang, J.-B.; Yu, Y. Controllable synthesis of self-assembled Cu르 nanostructures through a template-free polyol process for the degradation of organic pollutant under visible light. Mater. Res. Bull. 2009, 44, 1834-1841. [CrossRef]

3. Zhao, L.; Wang, H.; Huo, K.; Cui, L.; Zhang, W.; Ni, H.; Zhang, Y.; Wu, Z.; Chu, P.K. Antibacterial nano-structured titania coating incorporated with silver nanoparticles. Biomaterials 2011, 32, 5706-5716. [CrossRef] [PubMed]

4. Gentile, A.; Ruffino, F.; Grimaldi, M.G. Complex-Morphology Metal-Based Nanostructures: Fabrication, Characterization, and Applications. Nanomaterials 2016, 6, 110. [CrossRef] [PubMed]

5. Jeevanandam, J.; Barhoum, A.; Chan, Y.S.; Dufresne, A.; Danquah, M.K. Review on nanoparticles and nanostructured materials: History, sources, toxicity and regulations. Beil. J. Nanotechnol. 2018, 9, 1050-1074. [CrossRef]

6. Khan, I.; Saeed, K.; Khan, I. Nanoparticles: Properties, applications and toxicities. Arab. J. Chem. 2019, 12, 908-931. [CrossRef]

7. Yuan, Y.F.; Tu, J.P.; Wu, H.M.; Li, Y.; Shi, D.Q. Size and morphology effects of ZnO anode nanomaterials for Zn/Ni secondary batteries. Nanotechnology 2005, 16, 803-808. [CrossRef] 
8. Kar, P.; Farsinezhad, S.; Zhang, X.; Shankar, K. Anodic $\mathrm{Cu}_{2} \mathrm{~S}$ and $\mathrm{CuS}$ nanorod and nanowall arrays: Preparation, properties and application in $\mathrm{CO}_{2}$ photoreduction. Nanoscale 2014, 6, 14305-14318. [CrossRef]

9. Zhao, Y.; Burda, C. Development of plasmonic semiconductor nanomaterials with copper chalcogenides for a future with sustainable energy materials. Energy Environ. Sci. 2012, 5, 5564-5576. [CrossRef]

10. Wang, S.; Yang, S. Growth behaviour of straight crystalline copper sulphide nanowires. Adv. Mater. Opt. Electron. 2000, 10, 39-45. [CrossRef]

11. Li, L.; Zhang, W. Synthesis and light absorption properties of copper sulfide nanowire arrays on different substrates. Physica B 2018, 550, 26-31. [CrossRef]

12. Hsu, Y.-K.; Chen, Y.-C.; Lin, Y.-G. Synthesis of copper sulfide nanowire arrays for high-performance supercapacitors. Electrochim. Acta 2014, 139, 401-407. [CrossRef]

13. Ni, S.; Lv, X.; Li, T.; Yang, X. Fabrication of $\mathrm{Cu}_{2} \mathrm{~S}$ cathode for Li-ion battery via a low temperature dry thermal sulfuration method. Mater. Chem. Phys. 2013, 143, 349-354. [CrossRef]

14. Lai, C.-H.; Huang, K.-W.; Cheng, J.-H.; Lee, C.-Y.; Hwang, B.-J.; Chen, L.-J. Direct growth of high-rate capability and high capacity copper sulfide nanowire array cathodes for lithium-ion batteries. J. Mater. Chem. 2010, 20, 6638-6645. [CrossRef]

15. Feng, C.; Zhang, L.; Wang, Z.; Song, X.; Sun, K.; Wu, F.; Liu, G. Synthesis of copper sulfide nanowire bundles in a mixed solvent as a cathode material for lithium-ion batteries. J. Power Sources 2014, 269, 550-555. [CrossRef]

16. Daneshvar, N.; Salari, D.; Khataee, A.R. Photocatalytic degradation of azo dye acid red 14 in water on ZnO as an alternative catalyst to $\mathrm{TiO}_{2}$. J. Photochem. Photobiol. A 2004, 162, 317-322. [CrossRef]

17. Guettaï, N.; Ait Amar, H. Photocatalytic oxidation of methyl orange in presence of titanium dioxide in aqueous suspension. Part I: Parametric study. Desalination 2005, 185, 427-437. [CrossRef]

18. Chen, J.; Deng, S.Z.; Xu, N.S.; Wang, S.; Wen, X.; Yang, S.; Yang, C.; Wang, J.; Ge, W. Field emission from crystalline copper sulphide nanowire arrays. Appl. Phys. Lett. 2002, 80, 3620-3622. [CrossRef]

19. Rajeshwar, K.; Osugi, M.E.; Chanmanee, W.; Chenthamarakshan, C.R.; Zanoni, M.V.B.; Kajitvichyanukul, P.; Krishnan-Ayer, R. Heterogeneous photocatalytic treatment of organic dyes in air and aqueous media. J. Photochem. Photobiol. C 2008, 9, 171-192. [CrossRef]

20. Malato, S.; Fernández-Ibáñez, P.; Maldonado, M.I.; Blanco, J.; Gernjak, W. Decontamination and disinfection of water by solar photocatalysis: Recent overview and trends. Catal. Today 2009, 147, 1-59. [CrossRef]

21. Chen, C.-Y.; Cheng, K.-Y.; Chu, Y.-C.; Chen, L.-J.; Fang, W.-L.; Chang, C.-S.; Chou, L.-J. Liquid-Solid Process for Growing Gold Nanowires on an Indium Tin Oxide Substrate as Excellent Field Emitters. J. Phys. Chem. C 2012, 116, 12824-12828. [CrossRef]

22. Wu, Q.; Ren, S.; Deng, S.; Chen, J.; Xu, N. Growth of aligned $\mathrm{Cu}_{2} \mathrm{~S}$ nanowire arrays with AAO template and their field-emission properties. J. Vac. Sci. Technol. B 2004, 22, 1282. [CrossRef]

23. Barglik-Chory, C.; Remenyi, C.; Strohm, H.; Müller, G. Adjustment of the Band Gap Energies of Biostabilized CdS Nanoparticles by Application of Statistical Design of Experiments. J. Phys. Chem. B 2004, 108, 7637-7640. [CrossRef]

24. Wu, K.-J.; Chu, K.-C.; Chao, C.-Y.; Chen, Y.-F.; Lai, C.-W.; Kang, C.-C.; Chen, C.-Y.; Chou, P.-T. CdS Nanorods Imbedded in Liquid Crystal Cells for Smart Optoelectronic Devices. Nano Lett. 2007, 7, 1908-1913. [CrossRef]

25. Zhang, B.; Ye, X.; Hou, W.; Zhao, Y.; Xie, Y. Biomolecule-Assisted Synthesis and Electrochemical Hydrogen Storage of $\mathrm{Bi}_{2} \mathrm{~S}_{3}$ Flowerlike Patterns with Well-Aligned Nanorods. J. Phys. Chem. B 2006, 110, 8978-8985. [CrossRef]

26. Cao, B.L.; Jiang, Y.; Wang, C.; Wang, W.H.; Wang, L.Z.; Niu, M.; Zhang, W.J.; Li, Y.Q.; Lee, S. Synthesis and Lasing Properties of Highly Ordered CdS Nanowire Arrays. Adv. Funct. Mater. 2007, 17, 1501-1506. [CrossRef]

27. Grijalva, H.; Inoue, M.; Boggavarapu, S.; Calvert, P. Amorphous and crystalline copper sulfides, CuS. J. Mater. Chem. 1996, 6, 1157-1160. [CrossRef]

28. Chen, M.; Xie, Y.; Chen, H.; Qiao, Z.; Qian, Y. Preparation and Characterization of Metal Sulfides in Ethylenediamine under Ambient Conditions through a $\gamma$-Irradiation Route. J. Colloid Interface Sci. 2001, 237, 47-53. [CrossRef] 
29. Li, Y.; Wang, Z.; Ding, Y. Room Temperature Synthesis of Metal Chalcogenides in Ethylenediamine. Inorg. Chem. 1999, 38, 4737-4740. [CrossRef]

30. Qingqing, W.; Gang, X.; Gaorong, H. Solvothermal synthesis and characterization of uniform CdS nanowires in high yield. J. Solid State Chem. 2005, 178, 2680-2685. [CrossRef]

31. Wang, S.; Yang, S. Growth of Crystalline $\mathrm{Cu}_{2} \mathrm{~S}$ Nanowire Arrays on Copper Surface: Effect of Copper Surface Structure, Reagent Gas Composition, and Reaction Temperature. Chem. Mater. 2001, 13, 4794-4799. [CrossRef]

32. de Heer, W.A.; Châtelain, A.; Ugarte, D. A Carbon Nanotube Field-Emission Electron Source. Science 1995, 270, 1179. [CrossRef]

33. Chang, M.-T.; Chen, C.-Y.; Chou, L.-J.; Chen, L.-J. Core-Shell Chromium Silicide-Silicon Nanopillars: A Contact Material for Future Nanosystems. ACS Nano 2009, 3, 3776-3780. [CrossRef] [PubMed]

34. Schmitt, A.L.; Zhu, L.; Schmeißer, D.; Himpsel, F.J.; Jin, S. Metallic Single-Crystal CoSi Nanowires via Chemical Vapor Deposition of Single-Source Precursor. J. Phys. Chem. B 2006, 110, 18142-18146. [CrossRef]

35. She, J.; Xiao, Z.; Yang, Y.; Deng, S.; Chen, J.; Yang, G.; Xu, N. Correlation between Resistance and Field Emission Performance of Individual ZnO One-Dimensional Nanostructures. ACS Nano 2008, 2, 2015-2022. [CrossRef]

36. Chen, J.; Chen, Y.; Lin, Z.; Zhao, L.; Chen, D.; Wang, K.; Zhang, Z.; Zhang, G.; She, J.; Deng, S.; et al. Field Emission from Oxide Nanowires: Mechanism and Applications. In Proceedings of the 31st International Vacuum Nanoelectronics Conference (IVNC), Kyoto, Japan, 9-13 July 2018.

37. Juan, Y.M.; Hsueh, H.T.; Cheng, T.C.; Wu, C.W. Electron-Field-Emission Enhancement of CuO Nanowires by UV Illumination. ECS Solid State Lett. 2014, 3, P30-P32. [CrossRef]

38. Fowler, R.H.; Nordheim, L.W. Electron. Emission in Intense Electric Fields. Proc. Roy. Soc. Lond. A 1928, 119, 173-181.

39. Collins, P.G.; Zettl, A. Unique characteristics of cold cathode carbon-nanotube-matrix field emitters. Phys. Rev. B 1997, 55, 9391-9399. [CrossRef]

40. Chan, L.H.; Hong, K.H.; Xiao, D.Q.; Hsieh, W.J.; Lai, S.H.; Shih, H.C.; Lin, T.C.; Shieu, F.S.; Chen, K.J.; Cheng, H.C. Role of extrinsic atoms on the morphology and field emission properties of carbon nanotubes. Appl. Phys. Lett. 2003, 82, 4334-4336. [CrossRef]

41. Dimitrijevic, S.; Withers, J.C.; Mammana, V.P.; Monteiro, O.R.; Ager, J.W.; Brown, I.G. Electron emission from films of carbon nanotubes and ta-C coated nanotubes. Appl. Phys. Lett. 1999, 75, 2680-2682. [CrossRef]

42. Temple, D. Recent progress in field emitter array development for high performance applications. Mater. Sci. Eng. 1999, 24, 185-239. [CrossRef]

43. Zhong, D.Y.; Zhang, G.Y.; Liu, S.; Sakurai, T.; Wang, E.G. Universal field-emission model for carbon nanotubes on a metal tip. Appl. Phys. Lett. 2002, 80, 506-508. [CrossRef]

44. Xu, C.X.; Sun, X.W.; Chen, B.J. Field emission from gallium-doped zinc oxide nanofiber array. Appl. Phys. Lett. 2004, 84, 1540-1542. [CrossRef]

45. Hu, Y.; Zheng, Z.; Jia, H.; Tang, Y.; Zhang, L. Selective Synthesis of FeS and $\mathrm{FeS}_{2}$ Nanosheet Films on Iron Substrates as Novel Photocathodes for Tandem Dye-Sensitized Solar Cells. J. Phys. Chem. C 2008, 112, 13037-13042. [CrossRef]

46. Bo, X.; Bai, J.; Wang, L.; Guo, L. In situ growth of copper sulfide nanoparticles on ordered mesoporous carbon and their application as nonenzymatic amperometric sensor of hydrogen peroxide. Talanta 2010, 81, 339-345. [CrossRef] [PubMed]

47. Prieto, O.; Fermoso, J.; Nuñez, Y.; del Valle, J.L.; Irusta, R. Decolouration of textile dyes in wastewaters by photocatalysis with $\mathrm{TiO}_{2}$. Solar Energy 2005, 79, 376-383. [CrossRef]

48. Li, Y.; Somorjai, G.A. Nanoscale Advances in Catalysis and Energy Applications. Nano Lett. 2010, 10, 2289-2295. [CrossRef]

49. Bao, N.; Shen, L.; Takata, T.; Domen, K. Self-Templated Synthesis of Nanoporous CdS Nanostructures for Highly Efficient Photocatalytic Hydrogen Production under Visible Light. Chem. Mater. 2008, 20, 110-117. [CrossRef] 
50. Kudo, A.; Miseki, Y. Heterogeneous photocatalyst materials for water splitting. Chem. Soc. Rev. 2009, 38, 253-278. [CrossRef] [PubMed]

51. Wang, Q.; Lian, J.; Li, J.; Wang, R.; Huang, H.; Su, B.; Lei, Z. Highly Efficient Photocatalytic Hydrogen Production of Flower-like Cadmium Sulfide Decorated by Histidine. Sci. Rep. 2015, 5, 13593. [CrossRef]

(C) 2020 by the authors. Licensee MDPI, Basel, Switzerland. This article is an open access article distributed under the terms and conditions of the Creative Commons Attribution (CC BY) license (http://creativecommons.org/licenses/by/4.0/). 